\title{
$1 \quad$ Identifying the most relevant peers for benchmarking waste 2 management performance: a conditional directional distance Benefit-of-the-Doubt approach
}

\author{
Carolien Lavigne ${ }^{1}$ \\ Simon De Jaeger \\ Nicky Rogge \\ KU Leuven, Faculty of Economics and Business \\ ECON-CEDON Research Centre \\ Warmoesberg 26, 1000 Brussels
}

\begin{abstract}
The paper demonstrates that the outcome of the robust and conditional directional distance version of the BoD model not only contains information on the overall efficiency score and rank, but also enables a region to identify its genuine peers, disentangle the overall effect of the background conditions on the performance and assess one's relative strengths and relative weakness vis à vis its most relevant peers when evaluating its municipal solid waste management. We illustrate how this information can be retrieved from the outcomes of DEA/BoD based efficiency and performance benchmarking studies by applying the methodology to the case of the Brussels Capital Region. The results show that Freiburg, Darmstadt and the province of Limburg are in general the most interesting peers for the Brussels Capital Region. In addition, the analysis reveals that Darmstadt and Freiburg are identified as the most instructive peers if the region is interested in improving its composting and recycling rate, respectively.
\end{abstract}

Keywords: Composite Indicators; Benefit-of-the-Doubt; Regional Social Inclusion; Conditional BoD; Municipal Solid Waste; European Union.

\footnotetext{
${ }^{1}$ Corresponding author: Carolien Lavigne, Katholieke Universiteit Leuven (KU Leuven), Faculty of Economics and Business, Onderzoeksgroep ECON-CEDON, Warmoesberg 26, B-1000 Brussels, Tel.: +3226098264, email: carolien.lavigne@ kuleuven.be.

Abbreviations: Brussels Capital Region (BCR), Benefit-of-the-Doubt (BOD), municipal solid waste (MSW), composite indicator (CI), Externality Index (EI), Individual Index (II).
} 


\section{Introduction}

29 Inspired by the growing need for local and regional decision makers to constantly assess and adjust their municipal solid waste (MSW) management, we demonstrate how the output of the well-

31 known DEA/BoD based efficiency and performance benchmarking methodology contains

32 (besides an overall efficiency score and rank) crucial information that can assist the regions in identifying those management choices or policy initiatives that have the potential to improve

34 achievements of local waste management.

35 The study of efficiency in MSW management has gained interest both in political and academic 36 circles. Examples of academic studies include De Jaeger, Eyckmans, Rogge and Van Puyenbroeck 37 (2011), De Jaeger and Rogge (2013, 2014) and Rogge and De Jaeger (2013) for Belgium and Flanders, Dijkgraaf and Gradus (2004) for the Netherlands, Marques and Simões (2009), Simões, 39 De Witte and Marques (2010) and Simões and Marques (2012) for Portugal, Bosch, Pedraja and 40 Suárez-Pandiello (2000), Mateu-Sbert, Ricci-Cabello, Villalonga-Olives and Cabeza-Irigoyen 41 (2013) for Spain, Guerrini et al. (2017) for Italy, Worthington and Dollery (2001) for the UK, 42 Greene and Tonjes (2014) for the United States, and Johnstone and Labonne (2004), Picazo-Tadeo, 43 Castillo-Giménez and Beltrán-Esteve (2014) and Rogge, De Jaeger and Lavigne (2017) for 44 international studies. Examples of policy studies are BiPRO (2012), BiPRO/CRI (2015), European 45 Commission (2008), Eurostat (2012), and Forfás (2008). Most efficiency and benchmarking 46 studies of MSW management performances use non-parametric techniques such as the Data 47 Envelopment Analysis (DEA) methodology or the DEA based Benefit-of-the-Doubt (BoD) 48 methodology to capture the complexity and the multidimensionality of the MSW management 49 process. DEA is a non-parametric efficiency measurement technique originally developed by 50 Farrell (1957) and put into practice by Charnes, Cooper and Rhodes (1978) in the Operations 
51 Research and Management Science literature. They measure the relative efficiency performance

52 of a set of similar entities (organizations, production lines, regions, etc.) which employ (possibly)

53 multiple inputs to produce (possibly) multiple outputs in complex operating settings typically

54 characterized by a lack of reliable information on the prices of inputs and outputs and/or no (exact)

55 knowledge about the 'functional form' of the production or cost function. ${ }^{2}$ The BoD model is

56 tantamount to the DEA model in a 'pure output setting' in that one looks only at 'achievements'

57 (i.e., outputs) without taking into account the input side. Whereas the DEA-model evaluates the

58 efficiency/productivity of a MSW management process by estimating a ratio of weighted outputs

59 to weighted inputs, the BoD model assesses the performance of a MSW management process by constructing a composite (performance) indicator (CI, hereafter) using sub-indicators that typically

61 contain numerical information concerning relevant aspects of the MSW management process, such

62 as waste generation and treatment. The most important advantage of the DEA/BoD model is its

63 non-parametric nature. It allows for an endogenous (i.e. decided by the model instead of

64 predetermined) and optimal (i.e. a weighting that results in the highest possible ranking) weighting

65 of the multiple inputs and outputs (or, in case of the BoD model, the set of sub-indicators). More

66 specifically, the DEA/BoD model reconstructs 'implicit' weights ('shadow' prices for the inputs

67 and outputs in a DEA-setting or 'implicit' policy weights for the sub-indicators in the BoD setting)

68 from the observed data thereby looking for the set of weights that maximize for each evaluated

69 entity the relative performance score (efficiency score in DEA setting, composite policy

70 performance score in BoD setting). Stakeholders in a decision-making process often have different

71 opinions on the relative importance of the sub-indicators which makes deciding on a joint

\footnotetext{
${ }^{2}$ Other techniques are the parametric Stochastic Frontier Analysis (SFA)-method (Simões and Marques, 2011). For an extensive overview of different techniques, we refer the interested reader to Daraio and Simar (2007) or Fried, Lovell and Schmidt (2008).
} 
72 weighting scheme a difficult task. For example, one stakeholder may put more emphasis on waste

73 prevention while another wants to give a high weighting to proper waste treatment such as

74 incineration with energy recovery as opposed to without recovery. Also the trade-offs between the

75 importance of waste management inputs such as infrastructure, staff and the required surface area

76 and outputs such as waste processed and waste recycled are challenging in a multi-stakeholder

77 setting. This is therefore an attractive second best route in the absence of full information about

78 the true input/output prices (DEA setting) or policy priorities (BoD setting).

79 The large majority of efficiency and performance benchmarking studies of MSW management

80 provide policy makers and stakeholders with an efficiency/performance score and rank, which

81 denote how well each entity (region, municipality, etc.) is performing vis-à-vis the other entities.

82 In addition, some studies provide other more general insights such as how the operating

83 environment affects the efficiency/performance of MSW management (Simões \& Marques, 2011;

84 Rogge \& De Jaeger, 2012, 2013; Rogge et al., 2017), how the (cost) efficiency of MSW

85 management varies by the different MSW components (Rogge \& De Jaeger, 2012; 2013), how

86 different waste reduction and/or collection policies relate to the (cost) efficiency in collecting and

87 processing MSW (De Jaeger et al., 2011; Bosch et al., 2000) and how the size of waste

88 management utilities, waste pricing policies and/or incentive regulations impacts (cost) efficiency

89 in MSW services (Carvalho \& Marques, 2014; Carvalho, Marques \& Dollery, 2015; De Jaeger \&

90 Rogge, 2013; Marques \& Simões, 2009). Whereas such general measures and results are

91 particularly helpful for officials and policy makers at the higher policy levels (i.e., European

92 Commission), results of DEA based efficiency and benchmarking studies of MSW services also

93 comprise more detailed performance information and insights that are very useful and informative

94 for regional MSW management and policy makers. As opposed to the above papers, our approach 
consists in demonstrating how existing techniques in the BOD/DEA literature can be applied for identifying peers in the context of waste management in addition to a general ranking of the decision making units. Note that this approach has been applied in other fields of policy decisionmaking such as city performance in well-being and quality of life (Morais \& Camanho, 2011; Bernini, Guizzardi \& Angelini, 2013; Morais, Miguéis \& Camanho, 2013), promotion of sustainable tourism (Blancas, Caballero, González, Lozano-Oyola \& Pérez, 2010; Pérez, Guerrero, González, Pérez \& Caballero, 2013; Salvati \& Carlucci, 2014), urban water sector performance (Mbuvi, De Witte \& Perelman, 2012), urban green space use (Lopes \& Camanho, 2013), cities' livability (Zanella, Camanho \& Dias, 2015b), and public e-services (Reggi et. al, 2014). But to the best of our knowledge, this has not yet been used in the context of regional waste management evaluations.

As point of departure we take the outcomes of Rogge, De Jaeger and Lavigne (2017) which advocated the use of a robust and conditional directional distance version of the BoD model to measure (MSW) management performance of the NUTS2 regions in the EU ${ }^{3}$. It is elaborately described in their paper how this adjusted version of the BoD model enables to properly deal with the several methodological, conceptual and practical problems usually involved in the construction of a composite MSW management performance scores. The model is applied to European NUTS2 regions which is a geographical hierarchy level coinciding with a level between the national and municipality level. In short, this particular version of the BoD model allows to (1) treat subindicators measuring the different aspects of MSW management having different measurement units, while (2) adopting a flexible weighting method in an evaluation setting with no consensus among experts, policymakers and other stakeholders regarding the exact level of importance of

\footnotetext{
${ }^{3}$ As our paper builds on the same dataset (including the data manipulations), we refer Rogge et al. (2017) for a detailed description of the dataset
} 
117 different aspects of MSW performance. It (3) makes it possible to consider desirable indicators

118 (e.g., recycling rate) and undesirable indicators (e.g., disposal rate) in the measurement of regional

119 MSW performance and (4) reduces the impact of measurement errors and a-typical observations

120 in the data set. Furthermore, it (5) accounts explicitly for differences in the background conditions

121 under which the NUTS2 regions have to operate (given that the literature indicates that observed

122 differences in regional MSW performance may be partially driven by differences in background

123 conditions such as tourism or population density). However, whereas in the discussion of the

124 outcomes, Rogge et al. (2017) predominantly focused on describing the general results which are

125 informative predominantly for policy makers and stakeholders at higher policy making levels, the

126 present study delves deeper into the outcomes generated by the robust and conditional directional

127 distance version of the BoD model to look for insights and policy messages which are more useful

128 for regional policy makers, MSW management and stakeholders.

129 The key objective of the present paper consists in demonstrating how the outcomes of DEA/BoD 130 based efficiency and performance benchmarking studies of regional MSW services, besides 131 computing an overall efficiency score and rank for each region, contain also information that 132 enables to (1) identify peers for the evaluated region within and outside the policy maker's 133 jurisdiction, (2) identify which regions outperform other regions in terms of MSW management, 134 (3) interpret the region's MSW performance relative to the operating environment, and (4) identify 135 the basic functionalities of the regional MSW management on which the region performs relatively 136 highly and poorly (i.e. the basic functions of relative strength and relative weakness in the 137 evaluated MSW management's functioning). Note that the four types of information might seem 138 unrelated on first sight. In this paper we will however argue that combining 1-3 will allow a region 139 to identify its genuine peers in terms of performance, overall or partial superior performance and 
140 contextual characteristics while 4 will enable a region to assess one's relative strengths and relative

141 weaknesses vis à vis its most relevant peers. By combining all information (i.e. 1-4) a region will

142 be able to tell for each aspect of its MSW management which regions should be investigated in

143 more detail. Throughout, we illustrate how useful and informative information can be retrieved

144 from the outcomes of DEA/BoD based efficiency and performance benchmarking studies of

145 regional MSW services and performances with the case study of the Brussels Capital Region

146 (hereafter BCR with NUTS2 code BE10).

147 We selected the case of the BCR to illustrate the added value of identifying one's genuine peers

148 when selecting those management choices or policy initiatives that have the potential to improve

149 the region's waste management performance. In countries with (partly) decentralized waste

150 management competencies (such as Belgium), national environmental authorities are typically

151 interested in the peer comparability (and indeed comparison) of the (groups of) regions within their

152 jurisdiction. For instance, a first look at some key figures for the BCR seems to reveal that the

153 region is outperformed by the two other Belgian regions Flanders and Wallonia. In particular, the

154 percentage of municipal solid waste that is collected separately for recycling or recovery, is

155 considerably lower in the BCR compared to the other Belgian regions (see for instance Franklin,

156 2014). However, for the BCR, it remains difficult to assess the true bearing of such comparisons.

157 On the one hand differences in contextual characteristics (such as the prevailing metropolitan 158 context in the BCR with a higher population density and a higher level of tourism in the region)

159 might invalidate the comparison, but on the other hand it is important to understand which other 160 regions can indeed be seen as the region's genuine peers. Environmental authorities in the BCR 161 therefore (correctly) point out that a benchmarking exercises of regional waste management 162 performance should include 'comparable' peers. Nonetheless in many benchmarking exercises the 
pool of potential peers is confined to regions operating within the same country (or same overarching jurisdiction). This paper describes how a benchmarking study can be performed amongst regions with a variety of operating environments while at the same time accounting for their differences in the selection of peers.

167 This paper is organized as follows. Section 2 briefly presents the robust and conditional directional 168 distance version of the BoD model that was used in Rogge et al. (2017). Section 3 describes four methods in which a detailed analysis of the outcomes of BoD based performance benchmarking studies can be used by local policy makers when assessing their municipal solid waste (MSW) management performance. Finally Section 4 concludes.

\section{Conditional directional distance BoD model}

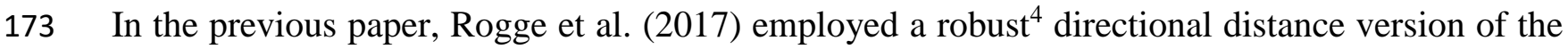
174 BoD model to measure and benchmark the MSW performances of NUTS2 regions in the EU. The 175 regions' MSW management performance was evaluated by constructing a composite indicator 176 derived from five sub-indicators which represent the different steps of the waste hierarchy ladder

177 (reduce, reuse, recycle, recover, landfill). The regional performance data originate from the 178 municipal waste generation and treatment dataset which is part of the 'Regional environmental 179 questionnaire Data' compiled by Eurostat, the statistical office of the EU ${ }^{5}$. The reduce step is 180 represented by the average municipal waste generation per capita. Unfortunately, no proper waste

\footnotetext{
${ }^{4}$ The model was robustified using the order-m approach presented by amongst others Cazals et al. (2002). An alternative to the order- $m$ approach of Cazals et al. (2002) is the order- $\alpha$ approach of Daouia and Simar (2007). The order-m approach was chosen as it enables an appealing economic interpretation, as it gives a clear indication of how well a region is performing relative to a subset of $\mathrm{m}$ regions.

${ }^{5}$ The data are publically available via the Eurostat database via http://ec.europa.eu/eurostat/web/regions/data/database. Metadata for this dataset can be downloaded via http://ec.europa.eu/eurostat/cache/metadata/en/env_rwas_gen_esms.htm
} 
181 reuse data was available on a European NUTS2 level. For the next step however, i.e. recycling,

182 two sub-indicators were used: the recycling rate and the composting rate. The fourth sub-indicator

183 is the percentage of incinerated municipal waste which is treated with energy recovery (denoted

184 'Recovery') (i.e. incineration that fulfils the energy efficiency criteria laid down in the Waste

185 Framework Directive, Annex II, recovery operation R1). Finally we included the proportion of

186 municipal waste which is landfilled (denoted 'Landfilling') which is the least favourable option.

187 Although these sub-indicators make sense in a European setting, different contexts may require

188 including alternative sub-indicators. For example in developing countries, when conducting a

189 waste management benchmarking study, using sub-indicators such as collection coverage and

190 disposal in controlled facilities versus open dumps could be more appropriate depending on the

191 local realities.

192 As this measurement involved a mixture of both desirable and undesirable performance criteria of

193 MSW performance, an additional adjustment of the model after Zanella, Camanho and Dias

194 (2015a) was implemented. The result was the following model (see also, Rogge et al., 2017 p. 24;

195 Zanella et al., 2015a p. 523):

$D_{k}=\min _{w_{k, r}^{+}, u_{k, l}^{-}}\left(-\sum_{r=1}^{s} w_{k, r}^{+} y_{k, r}^{+}+\sum_{l=1}^{m} u_{k, l}^{-} y_{k, l}^{-}+v\right)$

s.t.

$\sum_{r=1}^{s} w_{k, r}^{+} g_{r}^{+}+\sum_{l=1}^{m} u_{k, l}^{-} g_{l}^{-}=1$

$-\sum_{r=1}^{s} w_{k, r}^{+} y_{j, r}^{+}+\sum_{l=1}^{m} u_{k, l}^{-} y_{j, l}^{-}+v \geq 0 \quad(j=1, \ldots, N)$

$w_{k, r}^{+} \geq 0 \quad(r=1, \ldots, s)$

$u_{k, l}^{-} \geq 0 \quad(l=1, \ldots, m)$

$v \in \Re$ 
196 With $D_{k}\left(\boldsymbol{y}_{\boldsymbol{k}}^{-}, \boldsymbol{y}_{\boldsymbol{k}}^{+}, \boldsymbol{g}_{\boldsymbol{l}}^{-}, \boldsymbol{g}_{\boldsymbol{r}}^{+}\right)$the optimal directional distance value and $C I_{k}=1 /\left(1+D_{k}\right)$ the 197 associated composite MSW performance score for the evaluated region $k ; y_{k, r}^{+}(r=1, \ldots, s)$ and $y_{k, l}^{-}$ $198(l=1, \ldots, m)$ the performance values of the region $k$ on respectively the desirable MSW 199 performance criteria (i.e., 'Recycling', 'Composting', and 'Recovery', indexed r) and the 200 undesirable MSW performance criteria ('Waste generation' and 'Landfilling', indexed 1); $y_{j, r}^{+}$and $201 y_{j, l}^{-}$the performance values of all $N$ regions in the sample $(j=1, \ldots, k, \ldots, N)$ on the same performance 202 criteria; $w_{k, r}^{+}$and $u_{k, r}^{-}$the optimal BoD weights for region $k$ for the desirable and undesirable 203 performance criteria; and $\left(g_{l}^{-}, g_{r}^{+}\right) \in \mathbb{R}^{m+s}$ the direction vector which specifies for each MSW 204 performance criterion the exact direction in which improvements may be sought. The direction 205 vector was determined by the performance indicators for the region $k$ under evaluation.

206 In an attempt to fine-tune the model so as to obtain more realistic benchmarking results, Rogge et 207 al. (2017) appended the model in two ways. Firstly, two sets of weight restrictions were 208 implemented so as to mitigate an important downside to the large flexibility in weighting inherent 209 in the BoD model, i.e. CIs being constructed using improper weights. A first set of weight 210 restrictions imposed that all performance criteria should receive an importance weight of at least $2115 \%$ so as to avoid (quasi-) zero BoD weights. Formally,

$$
\begin{array}{cc}
\frac{w_{k, r}^{+} \overline{y_{r}^{+}}}{\sum_{r \prime=1}^{s} w_{k, r}^{+} \overline{y_{r^{\prime}}^{+}}+\sum_{l=1}^{m} u_{k, l}^{-} \overline{y_{l}^{-}}} \geq 0.05 \quad(r=1, \ldots, s) \\
\frac{w_{k, l}^{-} \overline{y_{l}^{-}}}{\sum_{r=1}^{s} w_{k, r}^{+} \overline{y_{r}^{+}}+\sum_{l \prime=1}^{m} u_{k, l}^{-} \overline{y_{l^{\prime}}^{-}}} \geq 0.05 \quad(l=1, \ldots, m)
\end{array}
$$

212 This implies the overall MSW performance score cannot be constructed while disregarding one or 213 more of the constituent performance criteria, a minimalist position which was taken to reflect the 
214 underlying idea that all performance criteria are considered as providing valuable MSW

215 performance information. A second set of weight restrictions was implemented so as to incorporate

216 the current policy stance in waste management in the EU. More specifically, this set of restrictions

217 imposed a rank ordering on the BoD importance weights for the MSW performance criteria that

218 corresponds to the waste hierarchy: the most important MSW performance criterion being 'Waste

219 Generation' followed by the MSW performance criteria 'Composting' and 'Recycling' and the

220 MSW performance criterion 'Recovery'. Following Zanella et al. (2015a), both types of weight

221 restrictions are imposed on the 'artificial' region representing the average performance values on

222 the desirable and undesirable criteria as computed across all regions in the sample. This ensures

223 that all regions are evaluated relative to a unique best practice frontier as weight restrictions are

224 uniform for all regions. Formally,

$$
\begin{aligned}
& w_{k, 1}^{-} \overline{y_{1}^{-}} \geq w_{k, 2}^{-} \overline{y_{2}^{-}}, w_{k, 1}^{-} \overline{y_{1}^{-}} \geq w_{k, 1}^{+} \overline{y_{1}^{+}}, w_{k, 1}^{-} \overline{y_{1}^{-}} \geq w_{k, 2}^{+} \overline{y_{2}^{+},} \\
& w_{k, 1}^{-} \overline{y_{1}^{-}} \geq w_{k, 3}^{+} \overline{y_{3}^{+}}, w_{k, 2}^{+} \overline{y_{2}^{+}} \geq w_{k, 1}^{+} \overline{y_{1}^{+}}, w_{k, 3}^{+} \overline{y_{3}^{+}} \geq w_{k, 1}^{+} \overline{y_{1}^{+}}
\end{aligned}
$$

225 A second way in which the BoD model as in (1) was fine-tuned was by using conditional (as 226 opposed to unconditional) version of this model (after insights of Cazals, Florens \& Simar, 2002;

227 Daraio \& Simar, 2007; De Witte \& Kortelainen, 2013; Bădin et al., 2010, 2012) so as to address

228 another important concern in the measurement and benchmarking of the MSW performances of

229 NUTS2 regions in the EU. NUTS2 regions perform under considerably different background

230 conditions including population density, GDP per capita, the number of nights spent at tourist

231 accommodation establishments per 1000 residents, the average wage for a worker in the MSW

232 sector and the number of enterprises (or part thereof) active in the regional MSW sector expressed

233 per 1000 inhabitants. This means that some regions work in more favorable and other regions in

234 less favorable operating environments. Such differences should be properly accounted for in the 
235 performance benchmarking analysis, which this method does. Otherwise, the regions may (not 236 entirely unjustifiably) criticize the outcomes of a comparative analysis and question the credibility 237 and validity of the assessment and benchmark instrument in general. The selection of background 238 characteristics is quite context-driven. Although these selected characteristics are relevant in a 239 European setting, a similar study on a different continent will probably require different 240 background characteristics to be taken into account. For example, studies analyzing both 241 developed and developing countries should probably include income levels as the size of local 242 MSW management budgets has an impact on a region's capability to implement the necessary 243 infrastructure to perform well in terms of MSW management. Furthermore the affordability of 244 more extensive waste management schemes impacts the willingness of the public to join the 245 schemes (in case of a voluntary scheme) or adhere to the rules (in case of a mandatory scheme). 246 The method for finding and evaluating peers however remains the same regardless of the chosen 247 background characteristics and the selected sub-indicators.

248 As noted in the introduction, Rogge et al. (2017) predominantly focused on describing the general 249 results, i.e. the BoD estimated MSW performance scores and ranks for the NUTS2 regions and the 250 relation between the regional MSW performance scores and operational environment. Regarding 251 the regional MSW performance scores and ranks, it was reported that (1) considerable differences 252 exist in the aggregate MSW performances of the regions, (2) the potential gains are considerable 253 for the waste sectors of many regions in the EU, (3) the NUTS2 regions in Austria, Belgium, and 254 Germany generally perform well in terms of MSW management and (4) the sub-indicator recycling 255 rate is the main factor differentiating the best performing countries from the worst. It was also 256 found that, except for the number of tourist overnight stays, background conditions are not 
257 significantly related to the MSW management performance of the waste sectors in the NUTS2

258 regions.

259 In the remainder, we delve deeper into the outcomes generated by the robust and conditional

260 directional distance version of the BoD model and, using as case study the BCR, illustrate how

261 these results can be used to look for insights and policy messages that could be useful for regional

262 policy makers, MSW management and stakeholders.

263

264

265

266

267

268

269

270

271

272

273

274 in terms of their background conditions, the conditional model generates Kernel density estimates.

275 For the calculation of the estimates, we refer the interested reader to Daraio and Simar (2007). In

276 doing so, the model assigns high Kernel density estimates (in this case a maximum of 0.1592) to

277 regions $j(j=1, \ldots, k, \ldots, N)$ with (very) similar background conditions to those of the evaluated

278 region $k$ and small (or even zero) Kernel density estimates to regions with (very) dissimilar 279 contextual characteristics. 
280

281

282

283

284

285

286

287

288

289

290

291

292

293

294

295

296

Table 1 lists the NUTS2 regions with the highest BoD generated Kernel density estimates or, in other words, the regions in the sample of $N$ regions with contextual characteristics that are overall most similar to the contextual characteristics of the BCR. The region most similar to the BCR is the BCR itself which is why it has the highest Kernel density estimate. The last two columns show the regions' unconditional and conditional (taking into account the operating environment) BODscores which represent their MSW management performance. In brackets, a number is provided which shows where the region is situated in the ranking in terms of the performance score of the 176 regions under study. There is no standard procedure to determine the number of regions that should be retained for detailed investigation. However, an interesting practical guideline consists in looking at the graphical representation of the regions sorted in decreasing order of their Kernel density estimate. Often, this graphical representation shows an "elbow"-function, with the graph displaying at first a steep drop in the Kernel density estimates up until the elbow point and a slow to very slow decline beyond this elbow point. The idea is to focus predominantly on those regions that are situated at the left of the elbow point as these regions operate under contextual characteristics more similar to the ones of region $k$. Figure 1 shows the graphical representation for the BCR. The plot displays an "elbow" around the 0.05-level, with 17 NUTS2 regions, including the BCR itself, having Kernel density estimates higher than this level.

\section{Table 1 around here}

\section{Figure 1 here}

Without information on how relevant the other regions are for constituting one's benchmark, the above Kernel density estimates remain insufficient to identify potential best practices. In addition to comparability of the operating environment, relevant peers should perform better than the region $k$ under study. A useful outcome of the BoD based performance benchmarking studies to 
complement the Kernel density estimates is the composition of the benchmark against which the

304 MSW performance of region $k$ is assessed ${ }^{6}$.

305 When constructing the composite indicator for a NUTS2 region, a hypothetical peer with its own

306 sub-indicator values is created. Region $k$ 's performance is assessed by evaluating how far away

307 region $k$ is from this hypothetical peer. This hypothetical peer is given sub-indicator values that

308 would result in the highest possible score when applying region $k$ 's optimal weightings. But at the

309 same time, we are comparing region $k$ to the other 175 regions which is why it also has to be a

310 linear combination of the 176 regions in the study. The model provides for each region a

311 hypothetical peer and accompanying coefficients for its linear combination. The coefficients of all

312 regions' linear combinations are $N$ vectors of intensities obtained from the dual version of the BoD

313 model. The BoD model hereby generates for each evaluated region $k$ a vector of intensities $\lambda_{k}=$

$314\left(\lambda_{k, 1}, \ldots, \lambda_{k, N}\right)$ which indicate how relevant other (observed) regions are for constituting the

315 benchmark against which the MSW performance of region $k$ is assessed. For a mathematical

316 formulation of the dual version and a detailed description of the intensity values, the interested

317 reader is referred to Zanella et al. (2015a).

318 As is described by Zanella et al. (2015a), this linear combination has typically only non-zero

319 lambda's for a small number of regions as the efficient frontier consists of facets in the hyperplane.

320 The previous study used a robust version of the BOD benchmarking analysis. The results were

321 robustified by creating $\mathrm{B}(=2500)$ composite indicators per region in which each iteration a

322 subsample of the $\mathrm{n}(=176)$ regions is selected (the order-m approach). The final composite

\footnotetext{
${ }^{6}$ Note that we used a simple version of the model in which the hypothetical peer is located at the cross-section between the efficient frontier and the directional distance vector (in our case the sub-indicator values of the NUTS2 region itself). Alternative techniques exist where a peer is selected which is closest to the region under evaluation in terms of the sub-indicators in order to find a direction of improvement which is easier to achieve, i.e. closest targets (see for instance Portela, Borges and Thanassoulis (2003) and Aparicio, Ruiz and Sirvent (2007)).
} 
323 indicators are calculated as the average of the B scores. The $\lambda$ 's presented in the intensity matrix

324 are the average values of the B $\lambda$ 's calculated for each region. Therefore, multiple (as opposed to

325 just a small number of) regions can be identified as peers as different subsamples will generate

326 different hypothetical peers. Furthermore, in the conditional version which takes into account the

327 operating environment, the selection of a subsample is not random, but based on how alike regions

328 are to the region for which we are constructing a composite indicator. Regions that are more alike

329 have a higher probability of being selected for subsamples.

330 The intensity matrix is the $N$ by $N$ matrix collecting the $(1 \mathrm{x} \mathrm{N})$ vectors of intensities for all $N$

331 NUTS2 regions in the sample. In the interpretation of the intensity values, non-zero values indicate

332 that a region acts as a peer of region $k$, with higher values indicating that this peer is a more

333 important role model for the region $k$ not only in terms of comparability of its operating

334 environment, but also in terms of its MSW management performance. In this case study, the 335 intensity matrix as computed by the robust and conditional BoD model is a 176x176 matrix. Due 336 to the vastness of the matrix, only one relevant part is presented in Table 2. Table 2 displays the 337 part of the intensity matrix that is associated with the BCR and the other Belgian NUTS2 regions 338 (next to the BCR there are ten NUTS2 regions in Belgium: Antwerpen (BE21), Limburg (BE22), 339 Oost-Vlaanderen (BE23), Vlaams-Brabant (BE24), West-Vlaanderen (BE25), Brabant Wallon 340 (BE31), Hainaut (BE32), Liege (BE33), Luxembourg (BE34), and Namur (BE35)).

342 Table 2 shows that the BCR is an important peer for its own MSW performance evaluation. Other 343 Belgian NUTS2 regions which are considered to some degree as benchmarks in the assessment of 344 the BCR's MSW performance are in decreasing order of importance Limburg (BE22), Namur 345 (BE35), Antwerpen (BE21), and Vlaams-Brabant (BE24). The intensity values displayed in Table 
2 indicate that the BCR is not a peer for the other Belgian NUTS2 regions (column 1). The diagonal elements in Table 2 show that in Flanders, three out of five regions (i.e., Limburg BE22, VlaamsBrabant BE24, and West-Vlaanderen BE25) act to some degree as their own peers in the measurement of their overall MSW performance. This can in part be attributed to their MSW management performance, but also to the fact that the region with the most comparable operating environment is itself. Furthermore, BE22, a region with comparable operating environment to the BCR (see Table 1) acts as a peer for the BCR while the opposite does not hold. We can therefore attribute a large part of intensity value 0.09 to BE22's MSW management performance. In addition, the intensity values for the Flemish NUTS2 regions reveals that BE24 plays the role of peer in the assessment of the MSW performance of one Flemish region (Oost-Vlaanderen BE23) and three Walloon regions (Brabant Wallon BE31, Hainaut BE32, and Liege BE33). Walloon regions only occasionally act as a peer for Belgian regions other than themselves (the only exception is Liege BE33 which acts to some extent as peer of Hainaut BE32).

Note though that the robust intensity values of most Belgian NUTS2 regions for the BCR are rather low as they can range between 0 and 1 . This suggests that other NUTS2 regions might be more interesting peers for the $\mathrm{BCR}$. In the case of the $\mathrm{BCR}$, a closer inspection of the entire $\mathrm{BoD}$ estimated intensity matrix ${ }^{7}$ in fact shows that the intensity estimates range between 0 and 0.33 . The BCR's highest intensity value is for the BCR itself. In addition to BE22, the regions DE13 (Freiburg) and DE14 (Tübbingen) with intensity values of 0.07 and 0.11 are two important peers in the evaluation of the MSW performance of the BCR, followed by DE12 (0.06), AT34 (0.06), DE11 (0.05) and BE35(0.04). Hence when the ambition of a benchmarking analysis extends beyond the construction of a pure ranking exercise and the ultimate goal is to identify those

\footnotetext{
${ }^{7}$ The full intensity matrix is available upon simple request.
} 
management choices or policy initiatives that have the potential to improve achievements of local waste management, the analysis shouldn't be confined to the peers within one's own jurisdiction. Note that combining the Kernel density estimates with the intensity values could help to identify the most interesting peers in terms of waste management performance and waste management policy choices. The first column of Table 1 shows the intensity levels that were obtained from the BoD based performance benchmarking of the BCR (i.e., $\lambda_{B C R, j}$ ) for the 17 selected regions. It can be readily observed from Table 1 that from this set of 17 regions with high Kernel density estimates, the NUTS2 regions Freiburg (DE13) and Limburg (BE22) combine the highest intensity levels with high unconditional and conditional BoD based MSW performance scores. This makes these two regions potentially interesting and informative best practice regions in MSW performance for the BCR. That is, in the design of reforms to improve MSW performance, the BCR could look to the MSW management of these regions (and search for what makes the MSW managements of these regions so successful).

\subsection{Dominance analysis}

When selecting the best practice regions it is important to consider the weighing scheme applied.

The BoD model endogenously calculates for each region $k$ the set of weights which optimizes its performance score vis-à-vis the other regions in the study. This results in N (here 176) sets of optimal weighting schemes. Generally, a region is said to dominate another region in its MSW performance if that region is always ranked higher than the other region, irrespective of the optimal weighting scheme applied in the evaluation of the MSW performances. In terms of improving the own MSW performance, it is interesting for a region to look at regions by which it is dominated, particularly in combination with the outcomes of the peer analysis (section 3.1). The outcomes of the BoD based performance benchmarking exercise can be used to assess different levels of 
391 dominance. As the BoD model is computed for each region $k(k=1, \ldots, N)$ and, in each of these

392 computations, optimal BoD weights of region $k$ are applied to all $N$ regions in the sample, each

393 region obtains $N$ BoD generated composite MSW performance scores and ranks. The $N$ x $N$ cross-

394 efficiency score and rank matrices group all these scores and ranks, respectively. A detailed study

395 of these matrices allows identifying which regions dominate other regions in their MSW

396 performance.

397 Figures $2 \mathrm{a}$ and $2 \mathrm{~b}$ portray for all NUTS2 regions in the sample the range of composite MSW

398 performance scores and ranks as retrieved from the cross-efficiency matrices. ${ }^{8}$ The black dot and

399 the blue cross on the intervals denote the arithmetic and the geometric means of the $N$ composite

400 MSW performance scores and ranks as computed for each region. For the BCR and the 16 NUTS2

401 regions with contextual characteristics similar to the ones of the BCR, ranges of scores and ranks

402 are presented in red.

\section{Figure 2 around here}

404 Note in Figure 2a that in terms of the composite MSW performance scores, one region is close to 405 being dominated by the BCR. Almost in all of the $N$ BoD computations, Basse Normandie (FR25)

406 obtains a composite MSW performance score that is lower that the score of the BCR. As to the

407 MSW rankings, Figure 2b shows that one region, i.e. Border, Midland and Western Ireland (IE01),

408 is fully dominated by the BCR. There are also two NUTS2 regions, Basse Normandie (FR25) and

409 Martinique (FR92), that are dominated by BCR in a large majority of the $N$ BoD computations

410 (the range of the BCR only overlapping marginally with the predominantly lower positioned

411 ranges of $\mathrm{BoD}$ based ranks for these regions). Figures $2 \mathrm{a}$ and $2 \mathrm{~b}$ also show that no region in the

\footnotetext{
${ }^{8}$ The figures display the composite MSW performance scores and ranks as computed by the unconditional version of the BoDmodel. The reason for doing so is that, when using the outcomes of the conditional BoD model, applying a region's optimal set of weights to a very dissimilar region, may result in extremely high or low scores. This is due to the fact that dissimilar regions are almost never selected in the sample when calculating the conditional scores.
} 
412 sample fully dominates the BCR, neither in terms of composite MSW performance score and rank.

413 Nonetheless, region Freiburg (DE13) with a relatively small range of the MSW performance

414 rankings (indicating that its rank is not much affected by the weights) is close to dominating the

415 BCR.

416 An alternative way to look for dominance results is less strong as the one discussed above. In

417 particular, instead of looking at dominance across all $N$ computations, one could also look for

418 dominance by comparing the BoD estimated composite MSW performance score of the evaluated

419 region $k$ with the MSW performance score as computed for the others regions when applying the

420 optimal BoD derived weights of the former region. In case that the evaluated region $k$ receives the

421 highest composite MSW performance score one could say that this region acts as its own

422 benchmark when being evaluated using the optimal evaluation parameters (i.e., using most

423 favorable weights). In the other scenario in which the evaluated region $k$ does not attain the highest

424 composite MSW performance score, a strong case (and a rather intuitive interpretation) can be

425 provided for the idea that the region $k$ is outperformed. In addition, the outperforming (set of)

426 region(s) can be regarded as best-practice benchmark(s) for the evaluated region $k$. Table 3 shows

427 how the composite MSW performance score of the BCR compares to the composite MSW scores

428 as computed for the other 16 regions with similar contextual characteristics (Sub-section 3.1) when

429 applying the optimal weights of the BCR. As can be seen in this table, BCR obtains a relatively

430 high composite MSW score which suggest that the BCR is identified as a relatively strong MSW

431 performer when being evaluated using its most optimal weights. On the other hand, Table 3 also

432 demonstrated that two other regions, Limburg (BE22) and Freiburg (DE13), do obtain higher

433 composite MSW performance scores even while using the BCR's optimal set of weights. Clearly

434 these regions outperform the BCR in terms of their MSW performance and are therefore interesting 
435 peers. Consequently, the above results of the peer and dominance analysis in mind, a policy

436 recommendation for the BCR would be to focus on Limburg (BE22) and Freiburg (DE13) for

437 further investigation.

438

439

440

441

442

443

444

445

446

447

448

449

450

451

452

453

454

455

456

457 hand, indicates how the region is able to cope with the background conditions. An $E I_{k}>1$ indicates

458 that region k's background conditions are favorable for its MSW management performance. An 459

\section{Table 3 around here}

\subsection{Decomposing composite MSW performance scores}

The identification of peers resulting from the above discussed peer and dominance analyses might indeed signal to regional policy makers which peers are best-in-class and can thus provide examples of well-performing sets of policies. Although the above discussed procedure already accounts for contextual differences, so far the procedure did not reveal how well (poorly) the regions under consideration and its peers are coping with the background conditions under which they have to operate. Nevertheless, such information could constitute key insights into potential successful adaptation strategies. Fortunately an analysis of the ratio of the conditional and unconditional composite MSW performance scores for the regions enables to disentangle the overall effect (positive or negative) of the background conditions on the regional MSW performance. The procedure of Daraio and Simar $(2006,2007)$ decomposes this ratio into three components: an internal or managerial MSW performance score, an 'Externality Index' and an 'Individual Index'. The internal or managerial MSW performance score is captured by the unconditional composite MSW performance score. The Externality Index $\left(E I_{k}\right)$ represents the overall effect of region $k$ 's operating environment (measured by the set of contextual characteristics) on its MSW management performance. The Individual Index $\left(I I_{k}\right)$ on the other $E I_{k}<1$ on the other hand, implies that the background conditions of region $\mathrm{k}$ are unfavorable for 
460 its MSW management performance. In the interpretation of the $I I_{k}$ values, an $I I_{k}$ larger than one

461 indicates that region $k$ performs better than the average region with similar background conditions.

462 In other words, region $k$ manages to take advantage of favorable background conditions or suffers

463 less from an unfavorable operating environment than what is to be expected. Regions with an $I I_{k}<1$

464 on the other hand underperform compared to the average region with similar background

465 conditions.

466 Figure $3 \mathrm{a}$ and $3 \mathrm{~b}$ respectively present the $95 \%$ confidence intervals of the mean $E I_{k}$ 's and the mean

$467 I I_{k}$ 's as computed by the robust versions of the BoD model for the NUTS2 regions in the sample.

468 The intervals for the BCR and the 16 regions with similar contextual characteristics highlighted in

469 red. Figure $3 a$ shows that the $E I_{k}$ values of the BCR and these 16 regions are quite similar, which

470 is to be expected as they indeed have similar background conditions. Figure $3 \mathrm{~b}$ demonstrates that

471 the $I I_{k}$ values for the NUTS 2-regions with contextual characteristics most similar to the BCR are

472 quite dispersed, with Freiburg (DE13) having the highest $I I_{k}$-value and Hamburg (DE60) the

473 lowest $I I_{k}$ value. As to the interpretation of the $E I_{k}$ and $I I_{k}$ values for the BCR, the $I I_{k}<1$ shows

474 that the BCR appears not to be able to take advantage of a mildly beneficial operating environment.

475 Other regions such as Freiburg (DE13), Limburg (BE22), NiederÖsterreich (AT12) and Noord-

476 Brabant (NL41) cope better with contextual characteristics similar to the ones of the BCR. On the

477 other hands, similarly to the BCR, regions such as Martinique (FR92), Zahodna Slovenija (SI02),

478 Hamburg (DE60), Southern \& Eastern Ireland (IE02) and Border, Midland, Western Ireland (IE01)

479 cope less well with similar contextual conditions. In order to evaluate whether $E I_{k}$ and $I I_{k}$ values

480 for the BCR differ statistically significantly from the values realized by the NUTS2 regions in the

481 sample with similar contextual characteristics, one could inspect closely the intervals depicted in

482 Figure $3 \mathrm{a}$ and $3 \mathrm{~b}$. The impact of the contextual characteristics is with high statistical significance 
more (less) favorable for MSW performance for region $k$ as compared to region $j$ if the interval for

$E I_{k}$ values for region $k$ is fully positioned above (below) the interval of the region $j$. Similarly, region $k$ is said to outperform another region $j$ in terms of coping better (worse) with the background conditions if the interval for $I I_{k}$ values for region $k$ is fully positioned above (below) the interval of the region $j$. Figure $3 \mathrm{~b}$ shows that in terms of coping with the contextual characteristics, the BCR only seems to outperform Martinique (FR92), Zahodna Slovenija (SI02) and Hamburg (DE60). However, the graph also shows that most of the NUTS2 regions with similar contextual characteristics cope better with these conditions.

\section{Figure 3 around here}

\subsection{Identifying strengths and weaknesses}

Identifying one's genuine peers in terms of general performance, overall or partial dominance and contextual characteristics is indeed a first and crucial step. Clearly for any benchmarking exercise to be useful for policy makers aiming at improving (regional) MSW performance, an overview of the aspects or sub-indicators where the region is performing strongly (poorly) compared to the other regions, is imperative. By combining such information with the results from the peer selection one will also be able to assess one's relative strengths and relative weakness vis à vis its most relevant peers. Given the multi-dimensional nature of the BoD based performance benchmarking methodology, the key building blocks for such analysis are to a large extend already endogenously determined in the model. Because of BoD's data-oriented and benevolent weighting of the sub-indicators in the construction of the composite MSW performance indicator, valuable insights on relative strengths and weaknesses can be inferred from looking at BoD estimated sub- 
508 indicator importance weights. ${ }^{9}$ In general, sub-indicators for which the BoD model assigns 509 relatively low importance weights (hence minimizing the impact of such sub-indicators) can be 510 considered as relative weaknesses in the region's MSW performance. The opposite holds for sub511 indicators for which the BoD model assigns relatively high importance weights, i.e. aspects of 512 relative strength in the region's MSW performance. This practical advantage of BoD weighting is 513 illustrated in Table 4 for the BCR and the regions that are most similar in terms of the operation 514 conditions. Although the peer and dominance analysis singled out Limburg (BE22) and Freiburg 515 (DE13) as interesting peers for the BCR, lessons can still be learned from an investigation of the 516 strengths and weaknesses of the other similar regions under evaluation. Some valuable insights 517 can be retrieved from Table 4. First, one readily notices that BoD obtained importance weights of 518 the sub-indicators can be quite diverse across the regions. This illustrates that the benefit of the 519 doubt principle in weighting plays an important role in the construction of the composite MSW 520 performance scores for the NUTS2 regions.

521 As to the identification of aspects of relative strength and relative weakness in the BCR's MSW 522 performance, the sub-indicator importance weights for the BCR show that a very high relative 523 weight is assigned to the sub-indicator measuring the proportion of MSW which is landfilled 524 (denoted 'Landfilling'). This indicates that the BCR is doing well on this MSW aspect, i.e. only a 525 very small fraction of MSW is landfilled by the BCR. The sub-indicator importance weight also 526 indicate that the BCR is doing relatively well in terms of waste generation and incineration with 527 energy recovery (minor relative strength). This shows that the comparative strengths and weaknesses using sub-indicator importance weights are a good representation of reality as BCR's

\footnotetext{
${ }^{9}$ For the desirable and undesirable sub-indicators, percentage contributions can be computed as respectively $w_{k, r}^{+} y_{r}^{+} /\left(\sum_{r=1}^{s} w_{k, r}^{+} y_{r}^{+}+\sum_{l=1}^{m} u_{k, l}^{-} y_{l}^{-}\right)$and $u_{k, l}^{-} y_{l}^{-} /\left(\sum_{r=1}^{s} w_{k, r}^{+} y_{r}^{+}+\sum_{l=1}^{m} u_{k, l}^{-} y_{l}^{-}\right)$. Note that, for the ease of interpretation, the weight restrictions were omitted when calculating relative strengths and weaknesses.
} 
MSW that is not recycled or composted is incinerated with energy recovery in an incinerator located on its territory. Furthermore, the sub-indicator importance weights show that the BCR is

531 performing relatively poorly on the aspects of composting and recycling MSW. From the point of

532 view of improving the overall MSW performance, the local policy makers in the MSW sector in 533 the BCR should aim at improving performance on the aspects of the MSW performance of relative 534 weaknesses while maintaining the good performance on the aspects of relative strength. In other 535 words, the BCR should particularly aim at increasing the composting and recycling of MSW. In 536 an attempt to gain knowledge on state of the art in composting and recycling, the BCR could learn 537 from regions with similar contextual characteristics that compost and/or recycle a high proportion 538 of their MSW. Looking at the sub-indicator importance weights for the sixteen regions that were 539 identified in the peer analysis as region with contextual characteristics that resemble the ones of 540 the BCR, we note that Hamburg (DE60) has a relative strength in waste generation and, to a lesser 541 extent, incineration with energy recovery, recycling and landfilling, while composting is its 542 relative weakness. Hamburg also has a lower composite MSW performance score. Note also that 543 Freiburg (DE13), which was in the peer and dominance analysis identified as one of the most 544 interesting peers to the BCR, has primarily a relative strength in recycling, but also, in decreasing 545 order, in incineration with energy recovery, composting and waste generation. When looking for 546 improvements in the composting policy, the BCR could have a look at Darmstadt (DE71).

547 Figure 4 visualizes the composite MSW performance scores and the sub-indicator importance 548 weights for the BCR and four peer regions. The pie share representation for the composite MSW 549 performance score of the BCR, clearly indicates that the BCR is performing very strongly on 550 landfilling as it disposes only a marginal (quasi zero) fraction of its MSW in landfilling and 551 relatively well in waste generation and incineration with energy recovery (both minor relative 
552 strengths). The (quasi-)zero importance weight for the other two sub-indicators ('composting' and

553 'recycling') in the construction of the BoD based composite MSW performance score indicate that

554 for the BCR these aspects of MSW are relative weaknesses.

555 Before concluding this paper, it is important to remark that one should be cautious in the 556 interpretation of the BoD generated sub-indicator importance weights as indications of MSW 557 aspects of relative strength and weakness. This because high (low) sub-indicator importance 558 weights may sometimes identify MSW-aspects as relative strengths or relative weaknesses in a 559 way that is difficult to justify. In particular, a sub-indicator might be identified by the BoD model 560 as a relative strength for a poorly-performing region and as a relative weakness in the MSW 561 performance of a highly-performing region, while the latter region performs better in absolute 562 terms on this sub-indicator. As an example, the BoD model identifies for Hamburg (DE60) the 563 sub-indicator 'waste generation' as a relative strength in the MSW performance largely because 564 of the region's performances on the other sub-indicators which are relatively even worse. For the 565 BCR, the sub-indicator 'waste generation' is identified only as a minor relative strength, even 566 though the BCR has lower waste generation per capita as compared to Hamburg. As argued by 567 Rogge (2011), such misinterpretations can be avoided by interpreting the BoD estimated sub568 indicator importance weights for the MSW sub-indicators in relation to the composite MSW 569 performance score.

570
Table 4 around here

Figure 4 around here

\section{Concluding remarks}


574 In this paper we demonstrated how the output of the well-known DEA/BoD based efficiency and

575 performance benchmarking methodology can be used to identify the most interesting and

576 informative best practice regions when aiming to improve one's MSW performance.

577 Applying this methodology to the case of the BCR indeed revealed which regions are the most 578 interesting peers in terms of waste management performance. Looking at the sub-indicator 579 importance weight additionally revealed that the BCR is performing relatively poorly on 580 composting and recycling of MSW. One could therefore argue that, if the BCR is interested in 581 improving its overall MSW performance, the BCR should primarily aim at increasing composting 582 and recycling rates of MSW. As most of Freiburg's strengths are found to be the BCR's relative 583 weaknesses and vice versa, an exchange of experiences between the two regions would be 584 mutually beneficial. Thus, in an attempt to improve recycling rates, looking at how Freiburg is 585 organizing the recycling of MSW might be a good place to start. When looking for improvements 586 in the composting policy, Darmstadt seems and interesting peer. Although Darmstadt is evaluated 587 with a lower composite MSW performance score, exchanging views on composting could prove 588 beneficial for the BCR. While being beyond the scope of this paper, but still a logical extension of 589 this research, we undertook a brief examination of the regions' waste management policies and 590 practices, which seems to confirm this observation. Upon inspection of the waste management 591 programs in place in Belgium and Germany, stricter resource-specific recycling targets were found 592 for packaging waste in Germany (Verordnung über die Vermeidung und Verwertung von 593 Verpackungsabfällen, 2017, Germany; Gesetz zur Fortentwicklung der haushaltsnahen 594 Getrennterfassung von wertstoffhaltigen Abfällen, 2017, Germany; Samenwerkingsakkoord van 4 595 november 2008 betreffende de preventie en het beheer van verpakkingsafval, 2008, Belgium). 596 Furthermore, separate collection of municipal solid bio-waste is mandatory in Germany (Gesetz 
zur Förderung der Kreislaufwirtschaft und Sicherung der umweltverträglichen Bewirtschaftung von Abfällen (Kreislaufwirtschaftsgesetz), Germany, 2012). Both Freiburg and Darmstadt are

located in the federal state (bundesland) Baden-Württemberg. As the federal states have a 600 considerable degree of autonomy in, among others, their waste management policies, the Baden601 Württemberg waste management plan (Abfallwirtschaftsplan Teilplan Siedlungsabfälle, 2017, 602 Germany) sets explicit targets for the separate collection of $60 \mathrm{~kg}$ per capita per year for 603 biodegradable kitchen waste and $90 \mathrm{~kg}$ for green garden waste to be attained by 2020 . In the 604 Brussels Capital Region however, although some green garden waste is collected separately and a 605 pilot project for food waste collection is under execution, separate collection of bio-waste remains 606 on a voluntary basis resulting in low collection rates. The above observations suggest that stricter 607 resource-specific targets for packaging waste accompanied with the introduction of a mandatory 608 separate collection of bio-waste could be a first step towards a more high-performing waste 609 management in the BCR.

610 This paper focused on identifying a region's most relevant peers rather than pinpointing the most 611 promising policy choices (or even operational decision). Clearly, identifying one's genuine peers 612 is a crucial first step, but when the ultimate goal is indeed to single out the best waste management 613 policy choices for the BCR, a more in-depth analysis of the selected peers is imperative. If one is 614 interested in assessing which policies might work and which policies are probably less suitable for 615 the BCR, the above analysis should be complemented with a more qualitative approach in which 616 the regional and local choices of the benchmarking regions are assessed and compared to the BCR 617 via for instance in-depth interviews with representatives of the regional environmental authorities. 618 By reducing the set of promising peers (and sub-aspect of each peers' MSW policy) via the 619 DEA/BoD based methodology proposed and elaborated in this paper, such typically time 
620 consuming approaches become a feasible option, thus facilitating and significantly improving 621 decision-making processes in municipal solid waste management. As a logical extension to this 622 study, a more in-depth analysis is a very promising route for further research. 


\section{Funding}

The authors gratefully acknowledge financial support of the Brussels Capital Region - Innoviris.

\section{Reference}

Aparicio, J., Ruiz, J. L., \& Sirvent, I. (2007). Closest targets and minimum distance to the Paretoefficient frontier in DEA. Journal of Productivity Analysis, 28(3), 209-218. BadenWürttemberg Ministry of Environment, Climate and Energy. (2017). Abfallwirtschaftsplan Teilplan Siedlungsabfälle. Retrieved from https://um.badenwuerttemberg.de/fileadmin/redaktion/mum/intern/Dateien/Dokumente/2_Presse_und_Service/Publikationen/Umwelt/AWP_BW_ TPSiedlAbfaelle.pdf

Bădin, L., Daraio, C., and Simar, L. (2010). Optimal bandwidth selection for conditional efficiency measures: A data-driven approach. European Journal of Operational Research, 201(2), 633-640.

Bădin, L., Daraio, C., \& Simar, L. (2012). How to measure the impact of environmental factors in a nonparametric production model. European Journal of Operational Research, 223(3), 818-833.

Bernini, C., Guizzardi, A., \& Angelini, G. (2013). DEA-like model and common weights approach for the construction of a subjective community well-being indicator. Social indicators research, 114(2), 405-424.BiPRO (2012). Screening of waste management performance of EU Member States. Report submitted under the EC project "Support to Member States in improving waste management based on assessment of Member States' performance". Report prepared for the European Commission, DG ENV, pp. 49.

BiPRO/CRI (2015). Assessment of separate collection schemes in the 28 capitals of the EU. Report prepared for the European Commission, DG ENV, pp. 161.

Blancas, F. J., Caballero, R., González, M., Lozano-Oyola, M., \& Pérez, F. (2010). Goal programming synthetic indicators: An application for sustainable tourism in Andalusian coastal counties. Ecological Economics, 69(11), 2158-2172.Bosch, N., Pedraja, F., \& Suárez-Pandiello, J. (2000). Measuring the efficiency of Spanish municipal refuse collection services. Local Government Studies, 26(3), 71-90.

Carvalho, P., Marques, R. C. (2014). Economies of size and density in municipal solid waste recycling in Portugal. Waste Management, 34, 12-20.

Carvalho, P., Marques, R. C., Dollery, B. (2015). Is bigger better? An empirical analysis of waste management in New South Wales. Waste Management, 39, 277-286. 
Cazals, C., Florens, J.P., \& Simar, L. (2002). Nonparametric frontier estimation: a robust approach. Journal of Econometrics, 106(1), 1-25.

Charnes, A., Cooper, W.W., \& Rhodes, E. (1978). Measuring the efficiency of decision making units. European Journal of Operational Research, 2(6), 429-444.

Daouia, A., \& Simar, L. (2007). Nonparametric efficiency analysis: a multivariate conditional quantile approach. Journal of Econometrics, 140(2), 375-400

Daraio, C., \& Simar, L. (2005). Introducing environmental variables in nonparametric frontier models: A probabilistic approach. Journal of Productivity Analysis, 24(1), 93-121.

Daraio, C., \& Simar, L. (2006). A robust nonparametric approach to evaluate and explain the performance of mutual funds. European Journal of Operational Research, 175(1), 516542.

Daraio, C., \& Simar, L. (2007). Advanced robust and nonparametric methods in efficiency analysis. Methodology and applications. Series: Studies in Productivity and Efficiency, Springer.

De Jaeger, S., Eyckmans, J., Rogge, N., \& Van Puyenbroeck, T. (2011). Wasteful waste-reducing policies? The impact of waste reduction policy instruments on collection and processing costs of municipal solid waste. Waste Management, 31(7), 1429-1440.

De Jaeger, S., Eyckmans, J., Rogge, N., \& Van Puyenbroeck, T. (2012). De efficiëntie van het gemeentelijk afvalbeleid. Vlaams Tijdschrift voor Overheidsmanagement, 2, 32-39.

De Jaeger, S., \& Rogge, N. (2013). Waste pricing policies and cost-efficiency in municipal waste services: the case of Flanders. Waste Management \& Research, 31(7), 751-758.

De Jaeger, S., \& Rogge, N. (2014). Cost-efficiency in packaging waste management: The case of Belgium. Resources, Conservation and Recycling, 85, 106-115.

De Witte, K., \& Kortelainen, M. (2013). What explains the performance of students in a heterogeneous environment? Conditional efficiency estimation with continuous and discrete environmental variables. Applied Economics, 45(17), 2401-2412.

Dijkgraaf E. \& Gradus R.H.J.M. (2004). Cost savings in unit-based pricing of household waste. The case of The Netherlands. Resource and Energy Economics, 26, 353-71.

European Commission (2008). Green Paper On the management of bio-waste in the European Union (COM(2008) 811 final). Available at: http://ec.europa.eu/green-papers/ [accessed on 4 February 2016], pp. 48.

Eurostat (2012). Guidance on municipal waste data collection. Report prepared by Eurostat -Unit E3 - Environment and forestry, pp. 12.

Farrell, M. J. (1957). The measurement of productive efficiency, Journal of the Royal Statistical Society, 120, 253-290. 
Forfás (2008). Waste Management Benchmarking Analysis and Policy Priorities. Report of the Department of Jobs, Enterprise and Innovation of Ireland, pp. 33.

Franklin, A. (2014). Brusselaars, Belgische afvalkampioenen? Focus 05 (Newsletter Brussels Instituut voor Statistiek en Analyse), pp. 8.

Fried, H., Lovell, C.A.K., Schmidt, S. (Eds.) (2008). The Measurement of Productive Efficiency and Productivity Growth (2nd Ed). Oxford University Press.

Germany, Bundesregierung. (1998). Verordnung über die Vermeidung und Verwertung von Verpackungsabfällen (Verpackungsverordnung - VerpackV). Bundesgesetzblatt, Jahrgang 1998, 1(56), pp. 2379-2389.

Germany, Bundesregierung. (2017). Gesetz zur Fortentwicklung der haushaltsnahen Getrennterfassung von wertstoffhaltigen Abfällen, 2017. Bundesgesetzblatt, Jahrgang 2017, 1(45), pp. 2234-2261.

Germany, Bundestag. (2012). Gesetz zur Förderung der Kreislaufwirtschaft und Sicherung der umweltverträglichen Bewirtschaftung von Abfällen (Kreislaufwirtschaftsgesetz - KrWG). Bundesgesetzblatt, Jahrgang 2012, 1(10), 212-264.

Greene, K., Tonjes, D. (2014). Quantitative assessments of municipal waste management systems: Using different indicators to compare and rank programs in New York State. Waste Management. 34(4), 825-836.

Guerrini, A., Carvalho, P., Romano, G., Marques, R.C., Leardini, C. (2017). Assessing efficiency drivers in municipal solid waste collection services through a non-parametric method. Journal of Cleaner Production. 147(20), 431-444.

Johnstone, N. \& Labonne, J. (2004). Generation of Household Solid Waste in OECD Countries: An Empirical Analysis Using Macroeconomic Data. Land Economics, 80, 529-538.

Lavee, D., \& Khatib, M. (2010). Benchmarking in municipal solid waste recycling. Waste Management, 30, 2204-2208.

Lopes, M. N., \& Camanho, A. S. (2013). Public green space use and consequences on urban vitality: An assessment of European cities. Social indicators research, 113(3), 751-767.

Marques, R. C., \& Simões, P. (2009). Incentive regulation and performance measurement of the Portuguese solid waste management services. Waste Management \& Research, 27(2), 188196.

Mateu-Sbert, J., Ricci-Cabello, I., Villalonga-Olives, E. \& Cabeza-Irigoyen, E. (2013). The impact of tourism on municipal solid waste generation: The case of Menorca Island (Spain). Waste Management, 33, 2589-2593.

Mbuvi, D., De Witte, K., \& Perelman, S. (2012). Urban water sector performance in Africa: A step-wise bias-corrected efficiency and effectiveness analysis. Utilities Policy, 22, 31-40. 
Morais, P., \& Camanho, A. S. (2011). Evaluation of performance of European cities with the aim to promote quality of life improvements. Omega, 39(4), 398-409.

Morais, P., Miguéis, V. L., \& Camanho, A. S. (2013). Quality of life experienced by human capital: An assessment of European cities. Social Indicators Research, 110(1), 187-206.

Pérez, V., Guerrero, F., González, M., Pérez, F., \& Caballero, R. (2013). Composite indicator for the assessment of sustainability: The case of Cuban nature-based tourism destinations. Ecological Indicators, 29, 316-324.

Picazo-Tadeo, a. J., Castillo-Giménez, J., Beltrán-Esteve, M. (2014). An intertemporal approach to measuring environmental performance with directional distance functions: Greenhouse gas emissions in the European Union. Ecological Economics, 100, 173-182.

Portela, M. C. A. S., Borges, P. C., \& Thanassoulis, E. (2003). Finding closest targets in nonoriented DEA models: the case of convex and non-convex technologies. Journal of Productivity Analysis, 19(2-3), 251-269.Rogge, N. (2012). Undesirable specialization in the construction of composite policy indicators: The environmental performance index. Ecological Indicators, 23, 143-154.

Reggi, L., Arduini, D., Biagetti, M., \& Zanfei, A. (2014). How advanced are Italian regions in terms of public e-services? The construction of a composite indicator to analyze patterns of innovation diffusion in the public sector. Telecommunications Policy, 38(5-6), 514-529.

Rogge, N., \& De Jaeger, S. (2012). Evaluating the efficiency of municipalities in collecting and processing municipal solid waste: A shared input DEA-model. Waste Management, 32(10), 1968-1978.

Rogge, N., \& De Jaeger, S. (2013). Measuring and explaining the cost efficiency of municipal solid waste collection and processing services. Omega, 41(4), 653-664.

Rogge, N., De Jaeger, S., \& Lavigne, C. (2017). Waste Performance of NUTS 2-regions in the EU: A Conditional Directional Distance Benefit-of-the-Doubt Model. Ecological Economics, 139, 19-32.

Rogge, N., \& Verschelde, M. (2013). A composite index of citizen satisfaction with local police services. Policing: An International Journal of Police Strategies \& Management, 36(2), 238-262.

Salvati, L., \& Carlucci, M. (2014). A composite index of sustainable development at the local scale: Italy as a case study. Ecological indicators, 43, 162-171.Simões, P., De Witte, K. \& Marques, R.C. (2010). Regulatory structures and operational environment in the Portuguese waste sector. Waste Management, 30, 1130-1137.

Simões, P., \& Marques, R. C. (2011). How does the operational environment affect utility performance? A parametric study on the waste sector. Resources, Conservation \& Recycling, 55(7), 695-702. 
Simões, P., \& Marques, R. C. (2012). Influence of regulation on the productivity of waste utilities. What can we learn with the Portuguese experience?. Waste Management, 32(6), 12661275.

Verschelde, M., \& Rogge, N. (2012). An environment-adjusted evaluation of citizen satisfaction with local police effectiveness: Evidence from a conditional Data Envelopment Analysis approach. European Journal of Operational Research, 223(1), 214-225.

Vlaamse Overheid, Brussels Hoofdstedelijk Gewest \& Waalse Overheidsdienst. (2008). Samenwerkingsakkoord van 4 november 2008 betreffende de preventie en het beheer van verpakkingsafval. Belgisch Staatsblad, jaargang 178, N.398, pp. 68366- 68423.

Worthington, A. C., \& Dollery, B. E. (2001). Measuring efficiency in local government: an analysis of New South Wales municipalities' domestic waste management function. Policy Studies Journal, 29(2), 232-249.

Zanella, A., Camanho, A.S., \& Dias, T.G. (2015a). Undesirable outputs and weighting schemes in composite indicators based on data envelopment analysis. European Journal of Operational Research, 245(2), 517-530.

Zanella, A., Camanho, A. S., \& Dias, T. G. (2015b). The assessment of cities' livability integrating human wellbeing and environmental impact. Annals of Operations Research, 226(1), 695726. 
Table 1: Similarity and performance of the Brussels Capital Region and similar regions

\begin{tabular}{l|l|l|l|l|}
\hline \hline \multicolumn{1}{|c|}{ Region } & $\begin{array}{c}\text { Kernel } \\
\text { density } \\
\text { estimate }\end{array}$ & $\begin{array}{c}\text { Intensity } \\
\text { levels } \lambda_{k, j}\end{array}$ & $\begin{array}{c}\text { Unconditional } \\
\text { BoD score } \\
\text { (rank) }\end{array}$ & $\begin{array}{c}\text { Conditional } \\
\text { BoD score } \\
\text { (rank) }\end{array}$ \\
\hline Brussels Capital Region (BE10) & 0.1592 & 0.332 & $0.967(45)$ & $0.980(42)$ \\
Hamburg (DE60) & 0.1562 & 0.000 & $0.815(105)$ & $0.853(104)$ \\
Oberpfalz (DE23) & 0.1421 & 0.005 & $0.990(40)$ & $0.975(45)$ \\
Noord-Brabant (NL41) & 0.1368 & 0.000 & $0.948(50)$ & $0.920(73)$ \\
Zahodna Slovenija (SI02) & 0.1289 & 0.000 & $0.815(106)$ & $0.849(106)$ \\
Overijssel (NL21) & 0.1223 & 0.001 & $0.915(68)$ & $0.900(81)$ \\
Southern \& Eastern Ireland (IE02) & 0.1180 & 0.000 & $0.709(155)$ & $0.726(149)$ \\
Gelderland (NL22) & 0.1138 & 0.004 & $0.961(47)$ & $0.934(64)$ \\
Luxembourg (LU) & 0.1040 & 0.000 & $0.747(133)$ & $0.742(142)$ \\
Darmstadt (DE71) & 0.1027 & 0.001 & $0.974(41)$ & $0.958(53)$ \\
Limburg (BE22) & 0.1022 & 0.090 & $1.104(10)$ & $1.043(7)$ \\
Freiburg (DE13) & 0.0946 & 0.066 & $1.098(11)$ & $1.046(6)$ \\
NiederÖsterreich (AT12) & 0.0890 & 0.000 & $1.021(29)$ & $0.989(39)$ \\
Martinique (FR92) & 0.0819 & 0.000 & $0.712(150)$ & $0.747(138)$ \\
Basse-Normandie (FR25) & 0.0676 & 0.000 & $0.693(163)$ & $0.696(162)$ \\
Mittelfranken (DE25) & 0.0658 & 0.000 & $0.928(61)$ & $0.925(70)$ \\
Border, Midland, Western Ireland (IE01) & 0.0508 & 0.000 & $0.693(162)$ & $0.709(155)$ \\
\hline \hline
\end{tabular}


Table 2: Intensity sub-matrix for the BCR and other Belgian NUTS2 regions

\begin{tabular}{l|ccccccccccc}
\hline \hline & BE10 & BE21 & BE22 & BE23 & BE24 & BE25 & BE31 & BE32 & BE33 & BE34 & BE35 \\
\hline BCR (BE10) & 0.33 & 0.03 & 0.09 & 0.00 & 0.01 & 0.00 & 0.01 & 0.00 & 0.01 & 0.00 & 0.04 \\
Antwerp (BE21) & 0.00 & 0.09 & 0.05 & 0.00 & 0.00 & 0.00 & 0.00 & 0.00 & 0.00 & 0.00 & 0.01 \\
Limburg (BE22) & 0.00 & 0.00 & 0.55 & 0.00 & 0.00 & 0.00 & 0.00 & 0.00 & 0.00 & 0.00 & 0.00 \\
East Flanders (BE23) & 0.00 & 0.00 & 0.02 & 0.03 & 0.25 & 0.00 & 0.07 & 0.00 & 0.00 & 0.00 & 0.03 \\
Flemish Brabant (BE24) & 0.00 & 0.00 & 0.00 & 0.01 & 0.83 & 0.00 & 0.04 & 0.00 & 0.00 & 0.00 & 0.02 \\
West Flanders (BE25) & 0.01 & 0.01 & 0.06 & 0.00 & 0.00 & 0.31 & 0.00 & 0.00 & 0.00 & 0.00 & 0.01 \\
Walloon Brabant (BE31) & 0.00 & 0.00 & 0.00 & 0.00 & 0.59 & 0.00 & 0.22 & 0.00 & 0.00 & 0.00 & 0.05 \\
Hainaut (BE32) & 0.00 & 0.00 & 0.00 & 0.00 & 0.38 & 0.00 & 0.07 & 0.00 & 0.22 & 0.00 & 0.06 \\
Liège (BE33) & 0.00 & 0.00 & 0.00 & 0.00 & 0.64 & 0.00 & 0.02 & 0.00 & 0.13 & 0.00 & 0.05 \\
Luxembourg (BE34) & 0.00 & 0.00 & 0.10 & 0.00 & 0.00 & 0.00 & 0.00 & 0.00 & 0.00 & 0.02 & 0.00 \\
Namur (BE35) & 0.00 & 0.01 & 0.03 & 0.01 & 0.10 & 0.00 & 0.01 & 0.00 & 0.01 & 0.00 & 0.27 \\
\hline \hline
\end{tabular}


Table 3: Composite MSW performance scores for the BCR and its peers as computed using $B C R$ 's optimal BoD-derived weights

\begin{tabular}{l|c|}
\hline \hline \multicolumn{1}{|c|}{ Region } & $\begin{array}{c}\text { Composite MSW- } \\
\text { performance score } \\
\text { using the BCR's } \\
\text { weights }\end{array}$ \\
\hline Brussels Capital Region (BE10) & 0.982 \\
Hamburg (DE60) & 0.728 \\
Oberpfalz (DE23) & 0.848 \\
Noord-Brabant (NL41) & 0.796 \\
Zahodna Slovenija (SI02) & 0.597 \\
Overijssel (NL21) & 0.841 \\
Southern \& Eastern Ireland (IE02) & 0.460 \\
Gelderland (NL22) & 0.851 \\
Luxembourg (LU) & 0.572 \\
Darmstadt (DE71) & 0.847 \\
Limburg (BE22) & 1.003 \\
Freiburg (DE13) & 0.983 \\
NiederÖsterreich (AT12) & 0.755 \\
Martinique (FR92) & 0.502 \\
Basse-Normandie (FR25) & 0.408 \\
Mittelfranken (DE25) & 0.782 \\
Border, Midland, Western Ireland (IE01) & 0.382 \\
\hline \hline
\end{tabular}


Table 4: Sub-indicator importance weights for Brussels Capital Region and its peers

\begin{tabular}{|c|c|c|c|c|c|c|}
\hline Region & $\begin{array}{l}\text { Conditional } \\
\text { BoD-score }\end{array}$ & Recovery & Composting & Recycling & $\begin{array}{c}\text { Waste } \\
\text { Generation }\end{array}$ & Landfilling \\
\hline Brussels Capital Region (BE10) & 0.980 & $4.8 \%$ & $0.0 \%$ & $0.2 \%$ & $5.0 \%$ & $90.1 \%$ \\
\hline Hamburg (DE60) & 0.851 & $11.4 \%$ & $0.1 \%$ & $4.1 \%$ & $77.1 \%$ & $7.2 \%$ \\
\hline Oberpfalz (DE23) & 0.976 & $14.5 \%$ & $38.5 \%$ & $5.6 \%$ & $40.4 \%$ & $1.0 \%$ \\
\hline Noord-Brabant (NL41) & 0.921 & $0.7 \%$ & $64.9 \%$ & $6.3 \%$ & $9.1 \%$ & $19.0 \%$ \\
\hline Zahodna Slovenija (SI02) & 0.847 & $33.7 \%$ & $0.0 \%$ & $23.9 \%$ & $42.0 \%$ & $0.4 \%$ \\
\hline Overijssel (NL21) & 0.900 & $3.2 \%$ & $36.4 \%$ & $1.4 \%$ & $39.6 \%$ & $19.4 \%$ \\
\hline Southern \& Eastern Ireland (IE02) & 0.726 & $88.6 \%$ & $0.0 \%$ & $10.4 \%$ & $0.8 \%$ & $0.2 \%$ \\
\hline Gelderland (NL22) & 0.935 & $0.3 \%$ & $51.9 \%$ & $1.5 \%$ & $27.0 \%$ & $19.3 \%$ \\
\hline Luxembourg (LU) & 0.741 & $93.8 \%$ & $0.9 \%$ & $4.8 \%$ & $0.1 \%$ & $0.4 \%$ \\
\hline Darmstadt (DE71) & 0.958 & $35.2 \%$ & $12.1 \%$ & $37.5 \%$ & $14.4 \%$ & $0.7 \%$ \\
\hline Limburg (BE22) & 1.044 & $0.6 \%$ & $20.5 \%$ & $0.6 \%$ & $5.7 \%$ & $72.6 \%$ \\
\hline Freiburg (DE13) & 1.046 & $22.3 \%$ & $11.9 \%$ & $57.3 \%$ & $7.1 \%$ & $1.5 \%$ \\
\hline NiederÖsterreich (AT12) & 0.988 & $9.2 \%$ & $83.6 \%$ & $0.0 \%$ & $2.0 \%$ & $5.2 \%$ \\
\hline Martinique (FR92) & 0.744 & $99.7 \%$ & $0.0 \%$ & $0.0 \%$ & $0.2 \%$ & $0.1 \%$ \\
\hline Basse-Normandie (FR25) & 0.696 & $98.5 \%$ & $1.1 \%$ & $0.3 \%$ & $0.1 \%$ & $0.0 \%$ \\
\hline Mittelfranken (DE25) & 0.925 & $22.7 \%$ & $26.1 \%$ & $16.0 \%$ & $34.7 \%$ & $0.5 \%$ \\
\hline Border, Midland, Western Ireland (IE01) & 0.710 & $89.1 \%$ & $0.0 \%$ & $10.2 \%$ & $0.6 \%$ & $0.1 \%$ \\
\hline
\end{tabular}

